\title{
Fazla Kilolu ve Obez Adölesanlarda Motivasyonel Görüşme Tekniğinin Kullanımı
}

\author{
Sonay BILGIN 國, Hasan EVCIMEN in $^{2}$
}

\begin{abstract}
ÖZ
Obezite tüm dünyayı etkileyen ve yetişkinlerde olduğu kadar son zamanlarda adölesan ve çocukluk çağındaki bireyleri de etkileyen bulaşıcı olmayan kronik bir hastalıktır. Obezitenin oluşumunda bireylerin sağlık davranışları büyük bir etkendir. Obezite tedavisini tek boyutta ele almak doğru bir yaklaşım olmayıp aynı zamanda davranış değişikliği ve kilo yönetimini de kapsamalıdır. Kilo yönetimi ve davranış değişikliği için kullanılan birçok mevcut yöntem olup bunlardan biri de motivasyonel görüşmedir. Motivasyonel görüşme danışan merkezli olup içsel görüyü ve aynı zamanda öz etkililiği de arttıran bir terapötik girişimdir. Motivasyonel görüşme farklı alanlarda kullanılmakla birlikte özellikle kilo verme, kilo kontrolü ve yönetimi, kronik hastalıklarda tedaviye uyum, sigara bırakma tedavisi ve maddenin kötüye kullanımı gibi davranış değişiminin yapılması gereken konularda kullanılmaktadır. Motivasyonel görüşmenin obez veya fazla kilolu adölesanlar üstünde davranış değişiminde etkili olduğu ve istendik yönde olumlu sağlık davranışlarının geliştirildiğini gösteren araştırmalar mevcuttur. Ancak motivasyonel görüşmenin klinik etkinliğini ortaya koymak ve kanıt düzeyini yükseltmek için konu ile ilgili daha fazla çalışmaya gereksinim bulunmaktadır. Bu derlemenin amacı fazla kilolu ve obez adölesanlarda motivasyonel görüşme tekniği kullanımının bireyler üstündeki etkilerini ortaya koymaktır.
\end{abstract}

Anahtar Kelimeler: Adölesan; motivasyon; görüşme; obezite; hemşirelik.

\section{The Use of Motivational Interview Technique in Overweight and Obese Adolescents}

\begin{abstract}
Obesity is a chronic disease that affects the whole world and is not contagious, affecting adults as well as recently adolescent and childhood individuals. Obesity is a major factor in the formation of individual's health behaviors. Treating obesity in one dimension is not the right approach, but should also include behavior change and weight management. There are many available methods for weight management and behavior change, one of which is motivational interviewing. Motivational interviewing is a therapeutic initiative that is client-centered and increases inner vision as well as self-efficacy. Motivational interviewing is used in different areas, but is particularly used in the areas of weight loss, weight control and management, adaptation to treatment in chronic diseases, smoking cessation therapy, and substance abuse. There are studies that show that motivational interviewing is effective in changing behavior on obese or overweight adolescents and that positive health behaviors are developed in the desired direction. However, further studies are needed to demonstrate the clinical efficacy of motivational interviewing and to raise the level of evidence. The aim of this review is to demonstrate the effects of motivational interviewing technique on individuals in overweight and obese adolescents.
\end{abstract}

Keywords: Adolescent; motivation; interview; obesity; nursing.

\section{GíRiş}

Dünya çapında erken morbidite ve mortalitenin başlıca nedeni olarak görülen obezite, ciddi bir halk sağglı̆̆ sorunudur $(1,2)$. Dünya Sağlık Örgütü’ne (DSÖ) göre obezite; morbidite mortalite risk seviyesini arttıracak derecede vücuttaki yăg dokusunun artmasıdır (3). Yetişkin obezitesi olduğu kadar çocukluk çağı obezitesi verileri de oldukça dikkat çekicidir (4). Çocukluk çağı obezitesi; 21.yy da hem gelişmiş hem de gelişmekte olan ülkelerde sağlık hizmeti sağlayıcıları

1 Atatürk Üniversitesi Hemşirelik Fakültesi, Halk Sağlığı Hemşireliği AD, Erzurum, Türkiye

2 Muş Alparslan Üniversitesi, Sağlık Hizmetleri Meslek Yüksekokulu, Terapi ve Rehabilitasyon Bölümü, Engelli Bakım ve Rehabilitasyon Programı, Muş, Türkiye 
arasında ciddi endişe uyandıran bir durumdur (5). Adölesan grup olan10-19 yaş arası fazla kilolu oranı 25 yılda \%6,8'den \%17,3'e yükselmiştir. Obezitedeki duruma bakıldığında ise 10-19 yaş arası grupta son 20 yılda dünya genelinde \%1,9'dan \%5,6'ya çıkmıştır. Obezite sıklığının en fazla olduğu yerler Amerika ve Avrupa kıtalarıdır. Dünyada olduğu gibi Türkiye'de de fazla kiloluluk ve obezite endişe verici bir hal almıştır. Türkiye 10-19 yaş arası adölesanlarda obezite sıklığının $\% 9,8$ olduğu saptanmıştır (6). Türkiye'de Sağlık Bakanlığı'nın yaptığı araştırmalarda $7-8$ yaş aralığında fazla kilolu çocuk sıklığının \%14,2-\%14,6 arasında olduğu obez çocuk sıklığının ise \%8,3-\%9,9 arasında olduğu bildirilmiştir (7).

Çocuklar arasındaki aşırı kilo alma durumu hem fiziksel hem de mental sağlığı olumsuz etkileyebilmektedir. Bu durum yalnızca yetişkinlik obezitesine neden olmamakla birlikte beraberinde tip 2 diyabet ve iskemik kalp hastalıklarına yakalanma riskini de arttırmaktadır $(8,9)$. Çocuk ve adölesanlara uygulanan davranışsal müdahalelerin, diyet ve fiziksel aktivite davranışlarını değiştirmede en etkili strateji olduğu belirtilmektedir (5). Mevcut kilo verme ve kilo yönetimi programlarının uzun vadeli kilo kontrolündeki merkezi rolüne rağmen, motivasyonun sürdürülmesine yönelik girişimlere az önem verdikleri görülmektedir. Bireyler kilo kaybını korumaya çalışırken motive kalmakta zorlanmaktadırlar. $\mathrm{Bu}$ nedenle, motivasyonel girişimler/müdahaleler becerilere dayalı ve eğitimsel yaklaşımlar kadar etkili olabilmektedir (10-12). Dünya ve Türkiye de en s1k görülen kronik hastalıklardan diyabet, hipertansiyon, kronik kalp hastalıkları gibi durumlarda motivasyonel görüşmenin hastalık yönetiminde oldukça etkili olduğu bulunmuştur (13). Taylor ve ark. (14) yapmış olduğu çalışmanın sonucunda, motivasyonel görüşmeye dayalı bireyselleştirilmiş erken müdahalelerin çocukların kilo vermelerinde etkili olduğu ve ailelere çocuklarının kilo durumu hakkında geri bildirim sağlamanın etkili yollarını belirlemede bir firsat sunduğunu belirtmişlerdir. Amerikan Pediatri Akademisi'de sağlık hizmeti sunucuları tarafindan yapılabilecek kilo kaybı ile ilgili davranış değişikliklerini teşvik etmede etkili bir yöntem olarak motivasyonel görüşmeyi (MG) önermektedir (15). MG, fazla kilolu ve obez adölesanların tedavisinde yaşam tarzı değişiminini teşvik eden ve danışan merkezli olan potansiyel bir yaklaşımdır (16). Pediatrik diyabet ve obezite konusundaki çalışmalara bakıldı̆̆ında duygusal, sosyal veya aile süreçlerini hedef alan çok bileşenli müdahalelerin, yalnızca doğrudan bir davranış sürecini hedefleyen müdahalelerden daha büyük bir etkisi olduğunu belirtmektedir. MG pediatrik obezitenin önlenmesinde ve yönetiminde rol oynayabilir. MG'nin pediatrik obezitede davranış değişikliğini nasıl etkileyebileceğini inceleyen çalışma mevcut olmakla birlikte sınırlı sayıdadır (17).Yapılan bir çalışmada bireysel MG müdahaleleri, vücut ağırlığının değişimi üzerinde az da olsa bir etkiye sahiptir ve davranışsal, psikososyal ve diğer değişkenler üzerinde olumlu bir etkiye sahip olabileceği düşünülmektedir. MG'nin etkililiğini ortaya koyabilmek için farklı değişkenler üstünde yapılacak çalışmalara ihtiyaç duyulmaktadır. Birinci basamak sağlı sistemi motivasyonel strateji hakkında verimli araştırmalar üretmek için avantajlı bir konumdadır (18). Bu derlemenin amacı fazla kilolu ve obez adöle sanlarda MG tekniği kullanımı ve bireyler üstündeki etkilerini ortaya koymaktır.

\section{Motivasyonel Görüşme ve Obezite}

Motivasyonel görüşme ilk kez Miller tarafından alkol bağımlısı yetişkinlerde kullanılmıştır, ayrıca MG'nin diğer sağlık davranışlarında da olumlu etkisi uygulama alanının genişlemesine neden olarak konuya olan ilgiyi artmıştır. Aynı zamanda MG tekniğinin terapötik işbirliği yoluyla davranış değişikliğini teşvik edici rolüde bulunmaktadır (16-20). MG tekniği bir süreç halinde ilerlemektedir. Hasta/ danışan kişinin, ilk aşamada değişime yönelik içsel motivasyonunun dışarı çıkarılması gerekmektedir. $\mathrm{Bu}$ aşamayı takiben davranış değişimine yönelik değişim planı oluşturulur. Bu plan doğrultusunda hasta/danışan kişinin istendik yönde davranış değişimine yönelik görüşmelere başlanır. Tüm bu uygulamaları yaparken MG'nin temel ilkelerinden yararlanılmalıdır (21-23).

Motivasyonel görüşmenin temel ilkeleri; empati gösterme, çelişkileri ortaya çıkarma, direnci kırma ve öz etkililiği desteklemektir (24).

Empati gösterme: Görüşmeci hasta/danışanın kabul edilmesini ve onun sorunlu olan davranışının onaylanmadığını belirtmek gerekir. Bireyle olumlu bir iletişim kurmak esastır (21).

Çelişkileri ortaya çıkarma: Danışman kişi hasta/danışanın mevcut davranışlarının hedeflediği nokta ile örtüşmediğini, mevcut durum ile olmak istediği durum arasındaki çelişkilerin ortaya çıkarılmasını vurgulamalıdır. Danışman kişi bu çelişkileri daha da derinleştirmeli, bunu yaparken de hasta/danışan bireye sorular sormalidir(21).

Direnci kırmak: MG'nin bu ilkesinde danışman kişi hasta/danışan bireyle gereksiz tartışmalara girmemeli ve bireyin önüne yeni hedefler koymamalıdır. Ancak hasta/danışan bireyin bakış açılarını kendisinin görmesini teşvik edici bir yaklaşım sergilemelidir (22).

Öz etkililiğin desteklenmesi: Davranış değişiminin sağlanmasında öz etkililiğin desteklenmesi önemli bir etkendir. $\mathrm{Bu}$ kapsamda danışman kişi hasta/danışan bireyin motivasyon düzeyinin yükseltilmesinde öz güvenin de olumlu şekilde desteklemelidir. Walpole ve ark. (25) yapmış oldukları çalışmada MG uygulanan bireylerin öz etkililiklerinin arttığı ve davranış değişimi noktasında bireylere olumlu destek sağladığı saptanmıştır. Bireylere öz güvenlerini destekleyici şekilde yaklaşımda bulunarak değişimin zorluklarını rahatça aşabilecekleri vurgulanmalıdır (23).

Son yillarda MG'nin adölesan grupta yapılan çalışmalarında artış olduğu görülmektedir $(14,16,17)$. Erikson tarafindan ortaya konulan Psikososyal Gelişim Kuramı'na göre adölesan dönemdeki bireylerin kimlik gelişimlerinin oluştuğu, aynı zamanda da rol karmaşası yaşadıkları belirtilmektedir. Adölesan dönemde yaşanan rol karmaşası, otonomi kurma düşünceleri bireyin riskli davranışlara olan eğilimini arttırabilmektedir. $\mathrm{Bu}$ riskli davranışlar adölesanlar da obeziteye neden olabilmektedir. Adölesanlarda rol karmaşası bireyleri obezitenin risk faktörleri olan sedanter yaşam, fiziksel aktivite azlığı, yeme bozukluklarına eğilimlerini arttırabilmekledir. $\mathrm{Bu}$ noktada $\mathrm{MG}$ adölesanların karmaşık duygularını ve kendi seçimlerini kabul ederek 
onları değişim için motive olmalarını sağlayabilmektedir. $\mathrm{Bu}$ bağlamda MG'nin adölesan gruptaki kullanımının yararlı olacağı belirtilmektedir $(24,26,27)$.

Hemşireler MG tekniğinin ilkelerini kullanarak obez adölesan bireylerde istendik yönde davranış değişimi sağlayabilmektedirler. $\mathrm{Bu}$ kapsamda obez adölesanla görüşen hemşirenin $\mathrm{MG}$ ilkelerinde biri olan empatik yaklaşımı kullanarak birey ile olumlu bir iletişim kurması gerekmektedir. Obez adölesanla görüşen hemşire değişimin önündeki engelleri anlamaya çalışmalı ve direnci çözmeye çalışmalıdır. Hemşire son olarak obez adölesanın öz etkililiğini destekleyerek davranış değişimine hazırlamalıdır. $(28,29)$

Motivasyonel görüşme yetişkin grupta olduğu gibi adölesan gruplarda da umut verici sonuçlar vermektedir. Yapılan çalışmalarda MG'nin uyku, fiziksel aktivite, egzersiz, tip 1 diyabetin yönetimi, kilo verme ve kilo kontrolü gibi konularda sağlığı olumlu yönde geliştirici etkisinin olduğu belirtilmiştir $(26,27)$. Ball ve ark. (30) 12-18 yaş arasında olan 46 adölesanla yapmış oldukları randomize kontrollü çalışmada deney grubundakilere MG tekniğini uygulamışlardır. Çalışma sonucunda deney grubundaki adölesanların beden kitle indeksi (BKI) Z skorunun kontrol grubundakilere göre anlamlı bir farklılık gösterdiği belirtilmiştir. Brennan'ın (31) 11-19 yaş aralığında olan 63 adölesanla yapmış olduğu randomize kontrollü çalışmada deney grubuna 60 dakikalık MG tekniği uygulanmış ve 4-6 ay takip edilmiştir. Çalışmada deney ve kontrol grubundaki adölesanların antropometrik ölçümleri(vücut yă̆ oranı, BKİ, üst orta kol çevresi), fiziksel aktiviteleri (bisiklet ergometre) ve metabolizma hızları (kalorimetre) izlenip ölçülmüştür. Çalışma sonucunda deney ve kontrol grubu arasında anlamlı bir farklılık gözlemlenmemiştir. Chalal ve ark. (32) tarafindan fazla kilolu ve obez olan adölesanlarda yapılan diğer bir çalışmada, bir grupta yalnız adölesanlara, diğer grupta ise adölesanlarla birlikte ebeveynlerine de MG uygulanmıştır. İki grupta da sağlıklı yaşam biçimi ve fizyolojik parametrelerdeki olumlu değişimlerin kazanılmasında etkin bir yöntem olduğu belirtilmiştir. Yapılan bir diğer çalışmada ise fazla kilolu ve obez olan 10-18 yaş arasındaki çocuk ve adölesanlara uygulanan MG'nin istendik yönde sağlık davranışlarının kazanılmasına pozitif etkisinin olduğu bildirilmiştir (33). Tripp ve ark. (34) 6 aylık bir pilot çalışmada 5-18 yaşlarındaki çocuğu olan 50 aileye birincil bakımda kanıta dayalı yönergeler sunmak için MG ilkelerini kullanmışlardır. Çocukların davranış değişimine olan tutumlarının düşük düzeyde kaldığını ancak BKİ'nin düşürülmesindeki eğilimlerinin daha iyi düzeyde olduğu iletilmiştir. Kelishadi ve ark. (35) yapmış oldukları nonrandomize çalışmada 457 çocuk için 24 haftalık motivasyonel yaşam tarzı modifikasyonu programı düzenlemişlerdir. Program kapsamında bir çocuk hekimi, iki genel hekim (aile hekimi) ve bir hemşire tarafindan sağlanan egzersiz, diyet eğitimi ve davranış modifikasyonunun üç bileşeni yer almaktadır. Program \%98 katılım oranı ile tamamlanmıştır. Çalışma sonuçları antropometrik ölçümlerde ve kardiyometabolik risk faktörlerin de önemli ölçüde azalış olduğu bildirilmiştir. Aynı zamanda ortalama yüksek yoğunluklu lipoprotein kolesterol (HDL-C) önemli ölçüde artmış, metabolik sendrom prevalansı ise $\% 20,8-\% 1,8$ arasında azalış göstermiştir. Yapılan bir başka randomize kontrollü çalışmada ise pediatristler tarafından 2-6 yaş arasındaki 475 çocuğa MG tekniği temelli televizyon, fastfood ve şekerli tatlandırılmış içecek alımına odaklı eğitim modülleri düzenlemiştir. MG temelli eğitim modüllerinin sadece müdahale grubundakilerin 12 ayda televizyon izleme oranını azalttığı saptanmıştır(36). MG uygulamalarını içeren diğer çalışmalarda da yeme davranışlarının ve obezite durumunun azaltılması noktasında olumlu yönde sonuçlar bildirildiği gözlemlenmiştir $(30,37)$. Okul tabanlı obeziteyi önleme programlarında da MG kullanılmaktadır. Örneğin; New Moves adı verilen ve adölesanlar için pilot bir okul tabanlı aktivite programına 16-18 yaşlarındaki 20 inaktif kız öğrenci katılmıştır. Yüksek katılımla devam eden programda aktivite, yeme düzeni ve beden imajıüzeylerine olumlu etkisi olduğu gözlemlenmiştir. Bununla birlikte MG, 38 Latin kökenli genç için devre (aerobik+kuvvet) eğitimi oturumlarına eklendiğinde kilo ile ilgili sonuçlar üzerinde hiçbir etkisinin olmadığı bildirilmiştir $(38,39)$.

\section{SONUÇ VE ÖNERILER}

Motivasyonel görüşme diyabet, hipertansiyon, obezite ve kronik kalp yetmezliği gibi birçok hastalıkta kullanılabilmektedir. Hastalarla sürekli iletişim halinde olan hemşirelerin, MG tekniğini kullanarak hastalığın yönetim ve iyi oluş süreçlerine olumlu yönde katkıları olacağı düşünülmektedir. MG tekniğinin özellikle çocuk ve adölesan obezlerde kilo kontrolünün sağlanmasında ve sürdürülmesinde etkili olduğu görülmektedir. Sağlık alanında çalışan sağlık profesyonellerinin özellikle de hemşirelerin $\mathrm{MG}$ tekniği konusundaki bilgi ve becerilerini arttırarak adölesan ve ailenin bakımında kullanmaları önerilmektedir. Hemşirelik temel müfredatında yer alan sağlık iletişimi, hasta iletişimi ya da kişilerarası iletişim derslerinde $\mathrm{MG}$ tekniğine yer verilmesi ile birlikte hemşirelerin terapötik iletişim becerilerinin gelişimi noktasında katkı sağlayacağı düşünülmektedir.

Yazarların Katkıları: Fikir/Kavram: S.B., H.E.; Tasarım: S.B., H.E.; Literatür Taraması: S.B., H.E.; Makale Yazımı: S.B., H.E.; Eleştirel İnceleme: S.B.

\section{KAYNAKLAR}

1. Digital.nhs.uk [Internet]. England: Health and Social Care Information Centre, Inc; c2015 [Updated: 2019 January 8; Cited: 2019 April 4]. Available from: http://www.hscic.gov.uk/catalogue/PUB16988/obesph ys-acti-diet-eng-2015.pdf.

2. Verma S, Hussain ME. Obesity and diabetes: An update. Diabetology \& Metabolic Syndrome. 2017; 11(1): 73-9.

3. Who.int [Internet]. Switzerland: WHO Document Production Services, Inc; c2000 [Updated: 2009 August 3; Cited: 2019 April 1]. Available from: https://www.who.int/nutrition/publications/obesity/W HO_TRS_894/en/.

4. Who.int [Internet]. Switzerland: WHO Document Production Services, Inc; c2015 [Updated: 2018 February 17; Cited: 2019 April 4]. Available 
from:https:/www.who.int/dietphysicalactivity/childh ood/en/.

5. Amiri P, Kazemian E, Mansouri-Tehrani MM, Khalili A, Amouzegar A. Does motivational interviewing improve the weight management process in adolescents? Protocol for a systematic review and meta-analysis. Systematic reviews. 2018; 7(1): 17885.

6. Who.int [Internet]. Switzerland: WHO Data Analaysis Services, Inc; c1975 [Updated: 2017 September 29; Cited: 2019 April 4]. Available from:http://apps.who.int/gho/data/view.main.BMIPL US2C10-19v?lang=en.

7. Esen İ, Ökdemir D. Çocukluk çağı obezitesi: Tanım, etiyoloji ve klinik değerlendirme. Frrat Tıp Dergisi. 2018; 23 (Supp): 92-9.

8. Sahoo K, Sahoo B, Choudhury AK, Sofi NY, Kumar R, Bhadoria AS. Childhood obesity: Causes and consequences. Journal of Family Medicine Primary Care. 2015; 4(2): 187-92.

9. Borrelli B, Tooley EM, Scott-Sheldon LAJ. Motivational interviewing for parent-child health interventions: a systematic review and meta-analysis. Pediatrics Dentistry. 2015; 37(3): 254-65.

10. West DS, Gorin AA, Subak LL, Foster G, Bragg C, Hecht J,et al. A motivation-focused weight loss maintenance program is an effective alternative to a skill-based approach. International Journal of Obesity. 2011; 35(2): 259-69.

11. Elfhag K, Rössner S. Who succeeds in maintaining weight loss? A conceptual review of factors associated with weight loss maintenance and weight again. Obesity Reviews. 2005; 6(1): 67-85.

12. Teixeira PJ, Going SB, Sardinha LB, Lohman TG. A review of psychological pre-treatment predictors of weight control. Obesity Reviews. 2005; 6(1): 43-65.

13. Arabacı Z, Doğru A, Yıldırım J. Kronik hastalıklarda transteoretik modele dayandırılarak motivasyonel görüşme tekniğinin kullanılması. Sağlık Akademisi Kastamonu. 2018; 3(2): 50-61.

14. Taylor RW, Brown D, Dawson AM, Hazar J, Cox A, Rose EA, et al. Motivational Interviewing for screening and feedback and encouraging lifestyle change to reduce relative weight in 4-8 year old children: design of the MinT Study. BMC Public Health. 2010; 10(1): 271-81.

15. Freira S, Lemos MS, Fonseca H, Williams G, Ribeiro M, Pena F, et al. Anthropometric out comes of a motivational interviewing school-based randomized trial involving adolescents with overweight. European Journal of Pediatrics. 2018; 177(7): 1121-30.

16. Miller WR, Rollnick S. Motivational interviewing: Helping people change. 3rd ed. New York: Guilford Press; 2013.

17. Christie D, Channon S. The potential for motivational interviewing to improve outcomes in the management of diabetes and obesity in pediatric and adult populations: a clinical review. Diabetes, Obesity and Metabolism. 2014; 16(5): 381-7.

18. Espinoza PG, San Carlos NG, Rojas DN, Rioseco RC. Es efectiva la entre vista motivational individual en la malnutrición porexceso? Una revisión sistemática de la literatura. Atención Primaria. 2018; 51(9): 548-61.
19. Chien WT, Mui JH, Cheung EF, Gray R. Effects of motivational interviewing based adherence therapy for schizophrenia spectrum disorders: a randomized controlled trial. Trials. 2015; 16(1): 270-83.

20. Lundah B, Moleni T, Burke BL, Butters R, Tollefson D, Butler C, et al. Motivational interviewing in medical care settings: a systematic review and metaanalysis of randomized controlled trials. Patient Education Counselling. 2013; 93(2): 157-68.

21. Armstrong MJ, Mottershead TA, Ronksley PE, Sigal RJ, Campbel TS, Hemmelgarn BR. Motivational interviewing to improve weight loss in overweight and/or obese patients: a systematic review and metaanalysis of randomized controlled trials. Obesity Reviews. 2011; 12(9): 709-23.

22. Rubak S, Sandbæk A, Lauritzen T, Christensen B. Motivational interviewing: A systematic review and meta-analysis. British Journal of General Practice. 2005; 55(513): 305-12.

23. Taşçı S, Özdemir H. Motivasyonel görüşme tekniği ve hemşirelikte kullanımı. Erciyes Üniversitesi Sağlık Bilimleri Fakültesi Dergisi. 2013; 1(1): 41-7.

24. Miller WR, Rollnick S. Motivational interviewing: Preparing people to change addictive behavior. New York: The Guildford Press; 2002.

25. Walpole B, Dettmer E, Morrongiello BA, McCrindle BW, Hamilton J. Motivational interviewing to enhance self-efficacy and promote weight loss in overweight and obese adolescents: a randomized controlled trial. Journal of Pediatric Psychology. 2013; 38(9): 944-53.

26. Naar-King S. Motivational interviewing in adolescent treatment. Canadian Journal of Psychiatry. 2011; 56(1): 651-7.

27. Gayes LA, Steele RG. A meta-analysis of motivational interviewing interventions for pediatric health behavior change. Journal of Consulting Clinical Psychology. 2014; 82(3): 521-35.

28. Flattum C, Friend S, Neumark-Sztainer D, Story M. Motivational interviewing as a component of a school-based obesity prevention program for adolescent girls. Journal of the American Dietetic Association. 2009; 109(1): 91-4.

29. Ball GDC, Mackenzie-Rife KA, Newton MS, Alloway CA, Slack JM, Plotnikoff RC, et al. One-onone lifestyle coaching form an aging adolescent obesity: Findings from a pilot, randomized controlled trial in a real-world, clinical setting. Paediatrics \& Child Health. 2011; 16(6): 345-50.

30. Brennan L. Does motivational interviewing improve retention or outcome in cognitive behavior therapy for overweight and obese adolescents?. Obesity Research Clinical Practice. 2016; 10(4): 481-6.

31. Chahal N, Rush J, Manlhiot C, Boydell KM, Jelen A, McCrindle BW. Dyslipidemia management in overweight or obese adolescents: A mixed-methods clinical trial of motivational interviewing. SAGE Open Medicine. 2017; 5(1): 1-15.

32. Walpole B,Dettmer E, Morrongiello B, McCrindle B, Hamilton J. Motivational interviewing as an intervention to increase adolescent self-efficacy and promote weight loss: Methodology and design. BMC Public Health. 2011; 11(1): 459-67. 
33. Tripp SB, Perry JT, Romney S, Blood-Siegfried J. Providers as weight coaches: using practice guides and motivational interview to treat obesity in the pediatric office. Journal of Pediatric Nursing. 2011; 26(5): 474-9.

34. Kelishadi R, Malekahmadi M, Hashemipour M, Soghrati M, Soghrati M, Mirmoghtadaee P, et al. Can a trial of motivational lifestyle counseling be effective for controlling childhood obesity and the associated cardiometabolic risk factors? Pediatrics \& Neonatology. 2012; 53(2): 90-7.

35. Taveras EM, Gortmaker SL, Hohman KH, Horan CM, Kleinman KP, Mitchell K, et al. Randomized controlled trial to improve primary care to prevent and manage childhood obesity: The high five for kids study. Archives of Pediatrics \& Adolescent Medicine. 2011; 165(8): 714-22.

36. MacDonell K, Brogan K, Naar-King S, Ellis D, Marshall S. A pilot study of motivational interviewing targeting weight-related behaviors in overweight or obese African American adolescents. Journal of Adolescent Health. 2012; 50(2): 201-3.

37. Flattum C, Friend S, Neumark-Sztainer D, Story M. Motivational interviewing as a component of a school-based obesity prevention program for adolescent girls. Journal of American Dietetic Association. 2009; 109(1): 91-4.

38. Neumark-Sztainer DR, Friend SE, Flattum CF, Hannan PJ, Story MT, Bauer KW, et al. New movespreventing weight-related problems in adolescent girls a group-randomized study. American Journal of Preventive Medicine. 2010; 39(5): 421-32.

39. Davis JN, Gyllenhammer LE, Vanni AA, Meija M, Tung A, Schroeder ET, et al. Startup circuit training program reduce metabolic risk in Latino adolescents. Medicine and Science Sports and Exercise. 2011; 43(11): 2195-203. 